\title{
Characterization of $\mathrm{SiC}: \mathrm{H}$ films deposited using HMDS precursor with $\mathrm{C}_{2} \mathrm{H}_{2}$ dilution gas by remote PECVD system
}

\author{
Sung Hyuk CHO and Doo Jin CHOI \\ Department of Ceramic Engineering, Yonsei University, 134 Shinchon-dong, Sudaemun-ku, Seoul 120-749, South Korea
}

\begin{abstract}
Amorphous SiC:H films were deposited on (100) silicon wafer by remote-Plasma Enhanced Chemical Vapor Deposition system in the temperature range of $400^{\circ} \mathrm{C}-450^{\circ} \mathrm{C}$. Hexamethyldisilane (HMDS) and $\mathrm{C}_{2} \mathrm{H}_{2}$ gas were used as a precursor and a dilution gas, respectively. The lower deposition temperature and lower $\mathrm{sp}^{3} / \mathrm{sp}^{2}$ carbon bonding ratio made lower dielectric constant. (c)2009 The Ceramic Society of Japan. All rights reserved.
\end{abstract}

Key-words : SiC:H, RPE-CVD, HMDS, Plasma, Low-k

[Received October 20, 2008; Accepted April 16, 2009]

\section{Introduction}

Recently, many deposition methods for $\mathrm{SiC}$ processes, including CVD,${ }^{1}$ sputtering, ${ }^{2)}$ and PECVD,${ }^{3)}$ have been researched and developed by various research groups. In general, $\mathrm{SiC}$ thin films deposited by plasma enhanced chemical vapor deposition (PECVD) at low temperatures show amorphous ${ }^{4}$ and hydrogenated properties in between the properties of organic and inorganic polymers, since source gases are decomposed to complex mixtures of monomers under plasma which react on the substrate at low temperatures. This is known as plasma polymerization, and this phenomenon is a general characteristic of films deposited by PECVD. ${ }^{5)}$ The amorphous and polymeric SiC film deposited by PECVD contains some hydrogen and oxygen in the film, which allows the possibility of using $\mathrm{SiC}$ films deposited by PECVD in low-k applications. (),7) The most commonly used low- $k$ material, fluorosilicate, has a $k$-value of 3.5, which is slightly lower than $\mathrm{SiO}_{2}$. In order to reduce the $\mathrm{RC}$ delay time, more low- $k$ materials with $k$-values less than 2 must be introduced. SiC deposited by PECVD is a potential candidate as a low- $k$ material. Among the PECVD methods, the remote PECVD (RPECVD) method has a relatively long distance from the plasma generation region to the film deposition area causing film damages and etching effects caused by a decrease of energetic ions. ${ }^{8), 9)}$ Using remote PECVD has advantages of easy control of reaction pathway and composition. In this study, we deposited SiC films by a remote PECVD system using HMDS (hexamethyldisilane) as a source and $\mathrm{C}_{2} \mathrm{H}_{2}$ as a dilution gas under various deposition temperatures, plasma powers, and dilution gas flow rates. X-ray photoelectron spectroscopy (XPS) and auger electron spectroscopy (AES) were used for the analysis of chemical compositions and bonding characteristics.

\section{Experimental}

The SiC films were deposited on (100) Si wafers by RPECVD using argon gas as the plasma source. Argon plasma was formed by a $13.56 \mathrm{MHz}$ RF plasma generator, and plasma matching was controlled by an auto-matching controller. The diameter of the susceptor was 4 inches, and the susceptor was about $20 \mathrm{~cm}$ away

Corresponding author: D. J. Choi; E-mail: drchoidj@yonsei.ac.kr from the plasma generation region. HMDS (hexamethylsisilane, $\left(\mathrm{CH}_{3}\right)_{6} \mathrm{Si}_{2}, 98 \%$, Aldrich) was used as the source and $\mathrm{H}_{2}$ gas was used as a carrier gas for the bubbled HMDS source. $\mathrm{C}_{2} \mathrm{H}_{2}$ gas was used as a dilution gas for carbon supplementation and controlling the carbon ratio in the film. The flow rates of the Ar, $\mathrm{H}_{2}$, and $\mathrm{C}_{2} \mathrm{H}_{2}$ gases were controlled by a mass flow controller (MFC), and the flow rate of the HMDS source was controlled by changing the flow rate of the carrier gas and line pressure. In this study, the flow rates of $\mathrm{Ar}$ and $\mathrm{H}_{2}$ gases were fixed at $200 \mathrm{sccm}$ and $50 \mathrm{sccm}$, respectively. The source line was shaped as a shower head with an angle of $90^{\circ} \mathrm{C}$ toward the plasma generation region to improve deposition uniformity. A SiC heating element was used to increase the temperature of the susceptor, and the actual deposition temperature on the wafer was corrected using a thermocouple. The deposition temperatures used were 400 and $450^{\circ} \mathrm{C}$. The flow rate of $\mathrm{C}_{2} \mathrm{H}_{2}$ was varied from $3 \mathrm{sccm}$ to $200 \mathrm{sccm}$ to investigate the effect of the carbon ratio on the dielectric constant. The plasma powers used were 200 and $300 \mathrm{~W}$. The relative ratios of silicon, oxygen, and carbon in the films were measured using X-ray photoelectron spectroscopy (XPS, VG Scientific, ESCALAB 220i-XL) and auger electron spectroscopy (AES, Physcial Electronics, PHI680 Auger Nanoprobe). The dielectric constant of the film was calculated through $C-V$ analysis using a Keithly $590 C-V$ analyzer at $1 \mathrm{MHz}$.

\section{Results and discussions}

Figure 1 shows the XRD analysis data of the $\mathrm{SiC}$ film deposited at $450^{\circ} \mathrm{C}$ and $300 \mathrm{~W}$ with a $\mathrm{C}_{2} \mathrm{H}_{2}$ flow rate of $3 \mathrm{sccm}$. The XRD analysis results showed that the deposited film was amorphous. In the XRD analysis, all of the samples deposited under the various deposition conditions showed amorphous states. The complex mixtures of decomposed monomers under plasma react on the substrate and cause amorphous $\mathrm{SiC}$ film deposition. It is known that amorphous $\mathrm{SiC}$, which contains some hydrogen and oxygen in the film, is highly crosslinked with each other and forms a random network structure with hydrocarbon groups $\left(-\mathrm{CH}_{\mathrm{n}}\right)^{\left.6,{ }^{6}, 7\right)}$ Figure 2 shows the dielectric constants at different deposition temperatures of 400 and $450^{\circ} \mathrm{C}$. As the deposition temperature was increased, the $\mathrm{sp}^{3}$ carbon bonding ratio and the dielectric constant increased. In our previous works, ${ }^{10), 11)}$ we showed that the $\mathrm{sp}^{3}$ carbon bonding ratio increased as the deposition temper- 


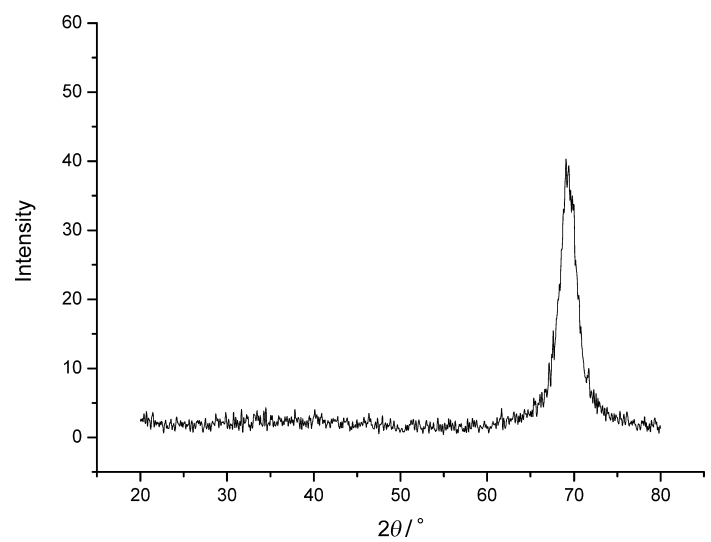

Fig. 1. XRD analysis data of the $\mathrm{SiC}$ film deposited at $450^{\circ} \mathrm{C}$ with a plasma power of $300 \mathrm{~W}$ and $\mathrm{a}_{2} \mathrm{H}_{2}$ flow rate of $3 \mathrm{sccm}$.

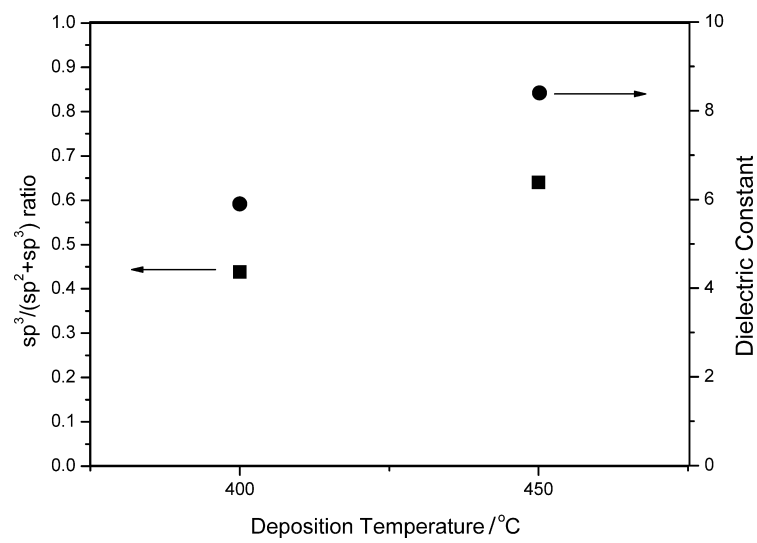

Fig. 2. Dielectric constant at deposition temperatures of 400 and $450^{\circ} \mathrm{C}$ with a plasma power of $300 \mathrm{~W}$ and a $\mathrm{C}_{2} \mathrm{H}_{2}$ flow rate of $3 \mathrm{sccm}$.

ature increased. The $\mathrm{sp}^{3}$ carbon bonding $\left(E_{\mathrm{a}}=70.7 \mathrm{kcal} / \mathrm{mol}\right.$, $\Delta H=13.4 \mathrm{kcal} / \mathrm{mol}$ ) has a higher activation energy than $\mathrm{sp}^{2}$ carbon bonding $\left(E_{\mathrm{a}}=50.3 \mathrm{kcal} / \mathrm{mol}, \Delta H=40.1 \mathrm{kcal} / \mathrm{mol}\right)$. Therefore, the $\mathrm{sp}^{2}$ reaction can occur more easily since its activation energy is lower than that of the $\mathrm{sp}^{3}$ reaction. However, the enthalpy $(\Delta H)$ of $\mathrm{sp}^{3}$ carbon bonding is lower than that of $\mathrm{sp}^{2}$ carbon bonding. Therefore, the $\mathrm{sp}^{3}$ reaction is more stable if sufficient energy (greater than the activation energy of $\mathrm{sp}^{3}$ ) is supplied at higher deposition temperatures. As shown in Fig. 2, $\mathrm{sp}^{3}$ bonding became dominant at $450^{\circ} \mathrm{C}$, as compared to $400^{\circ} \mathrm{C}$. In other studies, ${ }^{12), 13)}$ an increase of the $\mathrm{sp}^{3}$ bonding ratio resulted in increased film density, and a denser and harder film is deposited. Denser and harder films lead to an increase in the dielectric constant of the film. Also, as $\mathrm{sp}^{3}$ bonding increases, the $\mathrm{Si}-\mathrm{H}$ and $\mathrm{C}-\mathrm{H}$ bonds decrease due to bonding to each other to produce $\mathrm{sp}^{3}$ bonding. The increase of $\mathrm{Si}-\mathrm{H}$ and $\mathrm{C}-\mathrm{H}$ bonds leads to an increase in defect density and porosity in the film caused by an increase of meso porosity voids. ${ }^{7), 15}$ ) Therefore, the dielectric constant increases as the deposition temperature increases, since a denser and harder film is deposited due to the increase of $\mathrm{sp}^{3}$ bonding. Figure 3 shows the dielectric constants and carbon concentrations as a function of the $\mathrm{C}_{2} \mathrm{H}_{2}$ flow rate. As the $\mathrm{C}_{2} \mathrm{H}_{2}$ flow rate increased, the carbon concentration in the film increased. The $\mathrm{C}_{2} \mathrm{H}_{2}$ dilution gas is a carbon supplement gas for $\mathrm{SiC}$ film deposition, and the flow rate of $\mathrm{C}_{2} \mathrm{H}_{2}$ gas determines the carbon ratio in film. As shown in Fig. 3, the dielectric constant decreased as the $\mathrm{C}_{2} \mathrm{H}_{2}$ flow rate increased. However, the dielec-

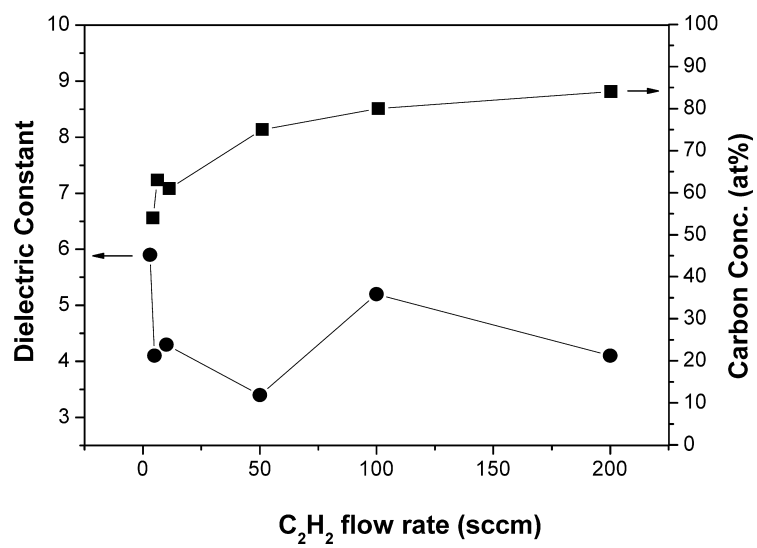

Fig. 3. Dielectric constant and carbon concentration as a function of $\mathrm{C}_{2} \mathrm{H}_{2}$ flow rate at a deposition temperature of $400^{\circ} \mathrm{C}$ and a plasma power of $300 \mathrm{~W}$.

tric constant increased at a $\mathrm{C}_{2} \mathrm{H}_{2}$ flow rate of $50 \mathrm{sccm}$. Studies of low- $k$ materials such as $\mathrm{SiOC}$ and hydrogenated $\mathrm{SiC}$ have determined that an increase in hydrocarbon groups leads to a porous network structure resulting in a decreased dielectric constant. ${ }^{7), 14)}$ As the $\mathrm{C}_{2} \mathrm{H}_{2}$ flow rate is increased, hydrocarbon related groups $\left(-\mathrm{CH}_{\mathrm{n}}\right)$ increase in the film resulting, in a decreased dielectric constant. However, as shown in the carbon concentration results in Fig. 3, the carbon concentration is saturated at $\mathrm{C}_{2} \mathrm{H}_{2}$ flow rates over $50 \mathrm{sccm}$. We showed that the $\mathrm{C}-\mathrm{C}$ bonding and $\mathrm{sp}^{3}$ carbon bonding increase as the $\mathrm{C}_{2} \mathrm{H}_{2}$ dilution gas flow rate is increased in our previous reports. ${ }^{10)}$ Saturated carbon particles react with each other under high energy at a plasma power of $300 \mathrm{~W}$, and carbon related bonding such as $\mathrm{C}-\mathrm{C}$ bonding and $\mathrm{sp}^{3}$ carbon bonding increase in the film. This increase in carbon related bonding, such as $\mathrm{sp}^{3}$ bonding, causes an increase in the dielectric constant. In other studies utilizing PECVD $\mathrm{SiC}^{\left.6,{ }^{6)} \text {, }\right)}$ an a-SiC:H film deposited using PECVD showed an amorphous and polymeric state. The additional energy and modified ratio of radicals cause the properties of carbon related groups to change. ${ }^{10), 11)}$ Since the carbon in the film exists in the form of $\mathrm{CH}_{\mathrm{n}}$ groups, this change in the carbon related groups affects the density, refractive index, hardness, and other film properties. Therefore, changes of not only the $\mathrm{C}_{2} \mathrm{H}_{2}$ flow rate but also the plasma power causes changes of the carbon related bonding type and carbon ratio. This leads to changes of the dielectric constant. Figure 4 shows the dielectric constant at different $\mathrm{C}_{2} \mathrm{H}_{2}$ flow rates and plasma powers. The dielectric constant of the film deposited at a plasma power of $200 \mathrm{~W}$ was lower than that deposited at $300 \mathrm{~W}$. As the plasma power is increased, the decomposition of source and dilution gases becomes easier and decomposed monomers react under the high plasma power. The increased energy at high plasma power produces strong and dense bonding, such as $\mathrm{sp}^{3}$ bonding, Si-C, and $\mathrm{C}-\mathrm{C}$ bonding, since the amount of decomposed radicals increases and radicals become more reactive at high plasma power. Therefore, as the plasma power increased, the dielectric constant increased since the increase of strong dense bonding produced denser deposited films. At the plasma power of $300 \mathrm{~W}$, the dielectric constant increased at $\mathrm{C}_{2} \mathrm{H}_{2}$ flow rates over $50 \mathrm{sccm}$ due to the saturated carbon reaction, as shown in Fig. 3. However, at the plasma power of $200 \mathrm{~W}$, the dielectric constant was similar or even lower at $\mathrm{C}_{2} \mathrm{H}_{2}$ flow rates over $50 \mathrm{sccm}$. At a plasma power of $300 \mathrm{~W}$, higher energy is supplied. This increased energy for strong bonding and the sufficient supply of saturated carbon at 


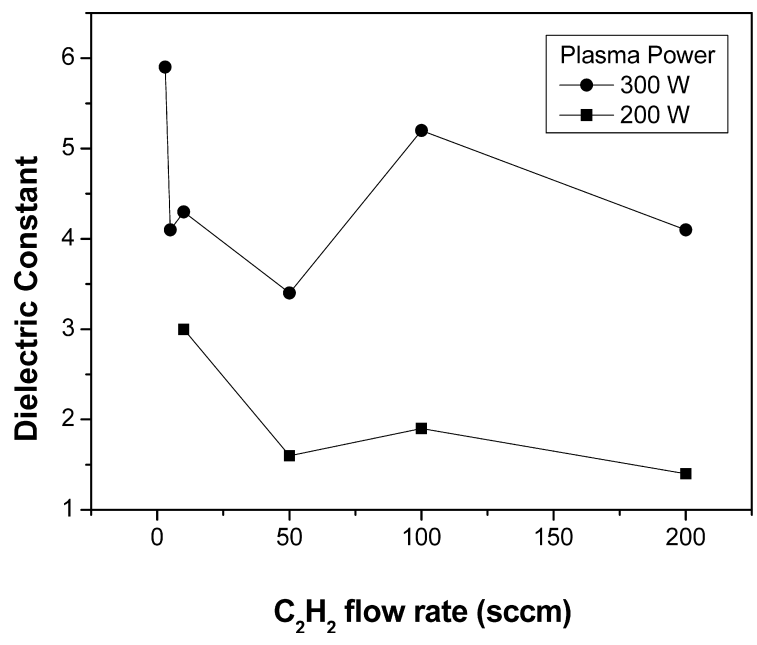

Fig. 4. Dielectric constant at different $\mathrm{C}_{2} \mathrm{H}_{2}$ flow rates and plasma powers at a deposition temperature of $400^{\circ} \mathrm{C}$.

$\mathrm{C}_{2} \mathrm{H}_{2}$ flow rates over $50 \mathrm{sccm}$ leads to increased strong and dense bonding, such as $\mathrm{sp}^{3}$ bonding. At a plasma power of $200 \mathrm{~W}$, the low plasma power causes the ratio of $\mathrm{CH}_{\mathrm{n}}$-like radicals to increase in the decomposed monomer, and the energy of the plasma power is insufficient for strong bonding such as $\mathrm{sp}^{3}$ carbon and $\mathrm{C}-\mathrm{C}$ bonding. Also, the amount of decomposed radicals under a plasma power of $200 \mathrm{~W}$ is less than that under a plasma power of $300 \mathrm{~W}$. The increase of the $\mathrm{C}_{2} \mathrm{H}_{2}$ flow rate above $50 \mathrm{sccm}$ causes the carbon ratio in the film to increase, and this increase in carbon bonding corresponds to increases in hydrocarbon and $\mathrm{sp}^{2}$ carbon bonding in the film since fewer radicals and the low plasma power are insufficient for $\mathrm{sp}^{3}$ carbon bonding. In other research regarding carbon bonding, ${ }^{16), 17)} \mathrm{sp}^{2}$ carbon bonding had the tendency to generate clusters rather than existing randomly in an amorphous matrix. These clusters make a ring or chain structure and bond to other carbon or hydrogen atoms around the cluster. In particular, the clustering of ring structures in the film increases as the ratio of $\mathrm{sp}^{2}$ bonding increases. The increase in ring and chain structures caused by an increase in $\mathrm{sp}^{2}$ bonding results in a more porous film. Also, $\mathrm{Si}-\mathrm{H}$ and $\mathrm{C}-\mathrm{H}$ bonds, which exist more with a plasma power of $200 \mathrm{~W}$ than in the film deposited at a plasma power of $300 \mathrm{~W}$, make the deposited film more porous. Therefore, the increase in hydrocarbon and $\mathrm{sp}^{2}$ bonding under the insufficient plasma power of $200 \mathrm{~W}$ leads to a decrease in the dielectric constant as the $\mathrm{C}_{2} \mathrm{H}_{2}$ flow rate increased from $50 \mathrm{sccm}$ to $200 \mathrm{sccm}$. Consequently, an amorphous $\mathrm{SiC}$ film with a dielectric constant under 2 can be achieved by deposition at a low plasma power of $200 \mathrm{~W}$ and a higher flow rate of $\mathrm{C}_{2} \mathrm{H}_{2}$ dilution gas. The deposition temperature, plasma power, and flow rate of dilution gas affected the dielectric constant of the film.

\section{Conclusion}

We deposited amorphous $\mathrm{SiC}$ films on (100) Si wafers by remote PECVD using HMDS and $\mathrm{C}_{2} \mathrm{H}_{2}$ gas as precursor and dilution gases, respectively. The deposition conditions, including temperature, plasma power, and $\mathrm{C}_{2} \mathrm{H}_{2}$ flow rate, were varied to investigate the effect of deposition conditions on the dielectric constant. As the deposition temperature increased, $\mathrm{sp}^{3}$ carbon bonding occured more frequently, causing an increase in the dielectric constant. At the high plasma power of $300 \mathrm{~W}$, the dielectric constant decreased up to a $\mathrm{C}_{2} \mathrm{H}_{2}$ flow rate of $50 \mathrm{sccm}$ and increased at $\mathrm{C}_{2} \mathrm{H}_{2}$ flow rates above $50 \mathrm{sccm}$. As the plasma power decreased, the dielectric constant decreased, and a dielectric constant under 2 was achieved at a low plasma power of $200 \mathrm{~W}$ and $\mathrm{C}_{2} \mathrm{H}_{2}$ flow rates above $50 \mathrm{sccm}$.

Acknowledgement This work was supported by DAPA and ADD.

\section{References}

1) A. Ellison, J. Zhang, W. Magnusson, A. Henry, Q. Wahab, J. P. Bergman, C. Hemmingsson, N.T. Son and E. Janzen, Mater. Sci. Forum, 131, 338 (2000).

2) A. K. Costa, S. S. Camargo Jr., C. A. Achete and R. Carius, Thin Solid Films, 243, 377 (2000).

3) T. Y. Lin, J. G. Duh, C. K. Chung and H. Niu, Jpn. J. Appl. Phys., Part 1, 39, 6663 (2000).

4) E. Bertran, E. Martinez, G. Viera, J. Farjas and P. Roura, Diamond Related Mater., 10, 1115 (2001).

5) H. Yasuda, "Plasma Polymerization," Academic Press, INC., New York (1985) pp. 4.

6) A. Grill and D. A. Neumayer, J. Appl. Phys., 94[10], 6697 (2003).

7) K. Maex, M. R. Barlanov, D. Shamaiyan, F. Lacopi, S. H. Brongerma and Z. S. Yanovitskaya, J. Appl. Phys., 93[11], 8793 (2003).

8) A. M. Wrobel, S. Wickramanayaka, K. Kitamura, Y. Nakanishi and Y. Hatanaka, Chemical Vapor Deposition, 6, 315 (2000)

9) A. M. Wrobel, A. Walkiewicz-Pietzykowska, J. E. KlembergSapieha, Y. Hanaka, T. Aoki and Y. Nakanishi, J. Appl. Polym. Sci., 86, 1445 (2002).

10) S. H. Cho, Y. J. Lee, D. J. Choi and T. S. Kim, J. Ecectroceram., 17, 811 (2006).

11) S. H. Cho, Y. J. Lee, D. J. Choi and T. S. Kim, J. Ceram. Process. Res., 8[6], 393 (2007).

12) V. V. Brazhkin, A. G. Lyapin and S. V. Popova, J. Appl. Phys., 84[1], 219 (1998).

13) S. Sattel, J. Robertson and H. Ehrhardt, J. Appl. Phys., 82[9], 4566 (1997).

14) S. K. Kwak, K. H. Jeong and S. W. Rhee, J. Electrochem. Soc., 151[2], F11 (2004).

15) G. Ambrosone, Philos. Mag. B, 82, 35 (2002).

16) J. Robertson and E. P. O'reilly, Phys. Rev. B., 35, 2946 (1987).

17) J. Robertson, Mater. Sci. Forum, 52, 125 (1990). 